\title{
Analysis of Technical Properties of Wind and Solar Photovoltaic Power
}

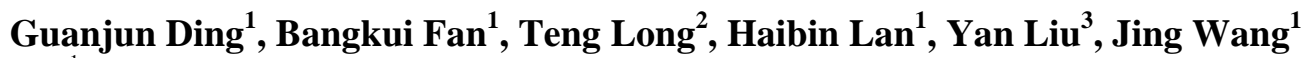 \\ ${ }^{1}$ Key Research Lab for Information, Beijing Information Technology Institute, Beijing, China \\ ${ }^{2}$ School of Information and Electronics, Beijing Institute of Technology, Beijing, China \\ ${ }^{3}$ School of Science, The Second Artillery Engineering University, Xi'an, China \\ Email: guanjunding@163.com
}

Received August 2013

\begin{abstract}
Most of electricity power in China comes from coal and hydropower. Already, China must import nearly half of its oil. Concerns about power capacity shortages and air pollution are all adding urgency and pressure to switch to alternative technologies and renewable energy. Among renewable energy sources, wind power and solar photovoltaic power are playing key roles in China, and are the fastest-growing power generation technologies. So this paper focuses on them and analyzes the corresponding technical properties of them. First of all, wind power transforms the kinetic energy from the wind into electricity by using wind turbines. Thus the basic components of wind turbines are described. Wind speed is an important factor to wind energy. So the features of wind speed are analyzed, and the wind energy is calculated. Second, the technical properties of solar photovoltaic power are discussed, including photovoltaic cells and modules, battery, inverter and photovoltaic controller. Photovoltaic energy is also analyzed and calculated. Third, the environmental impacts of wind power and solar photovoltaic power are presented. Finally, the relevant conclusions are drawn.
\end{abstract}

Keywords: Wind Power; Solar Photovoltaic Power; Technical Properties; Environmental Impacts

\section{Introduction}

With the serious problem of environmental pollution caused by fossil fuel, wind and solar photovoltaic power have emerged as two of the most attractive clean technologies and they are planned to be major sources of future electricity needs [1]. Wind and solar photovoltaic power have gained extensive interests, and they are the most mature and cost effective resources among different renewable energy technologies [2].

Wind power is a source of renewable power which comes from air current flowing across the earth's surface. Solar photovoltaic power comes from the sunlight irradiates the earth's surface. They are affordable and sustainable. Since wind and sunlight are free and inexhaustible, the price of wind and solar photovoltaic power is stable, which is unlike electricity from fossil fuel powered source that depends on fuel whose price is costly and may vary considerably. Nevertheless, the major challenge of wind and solar photovoltaic power is that they are the intermittent power supplies, because wind doesn't always blow and sometimes there is no sunlight. Figure 1 shows the intermittent nature of wind power.

Due to the intermittency characteristics of wind and solar photovoltaic power, it results in the variability, unpredictability, and uncertainty of wind and solar sources
[3]. Thus the integration of wind and solar facilities to utility grid presents a major challenge to power system operator, it would cause some problems when integrating a large amount of wind and solar photovoltaic power into the existing electrical grid. Such integration has significant impact on the optimum power flow, transmission congestion, power quality issues, system stability, load patch, etc. $[4,5]$. So, in order to analyze the impacts on power system plan and operation in depth, the technical properties of wind and solar photovoltaic power must be considered. This is the aim of this paper. The paper analyzes and studies the corresponding technical properties, including wind turbine, wind speed, wind power and energy, photovoltaic cells and modules, battery and inverter, photovoltaic controller and energy, to provide the analysis basis and reference for further research of power system containing wind and solar power.

\section{Technical Properties of Wind Power}

\subsection{Wind Turbine}

A wind turbine is the machine which converts the kinetic energy from wind into mechanical energy [6], as shown in Figure 2. The mechanical energy is then converted to electricity. The modern wind turbine is a sophisticated 


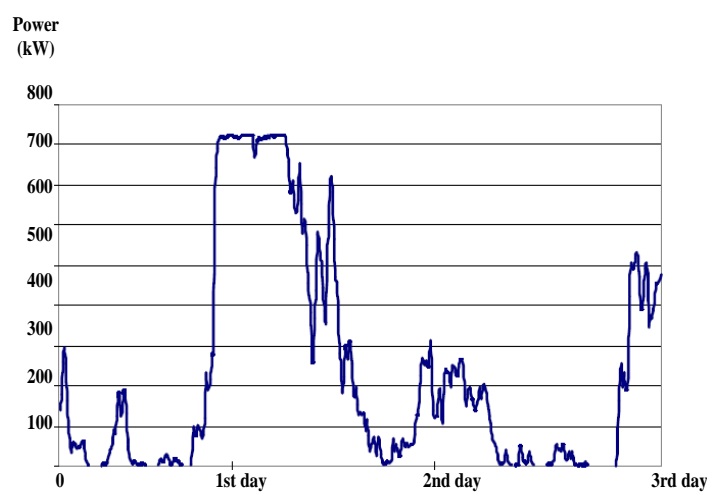

Figure 1. Diagram of the intermittent nature of wind power.

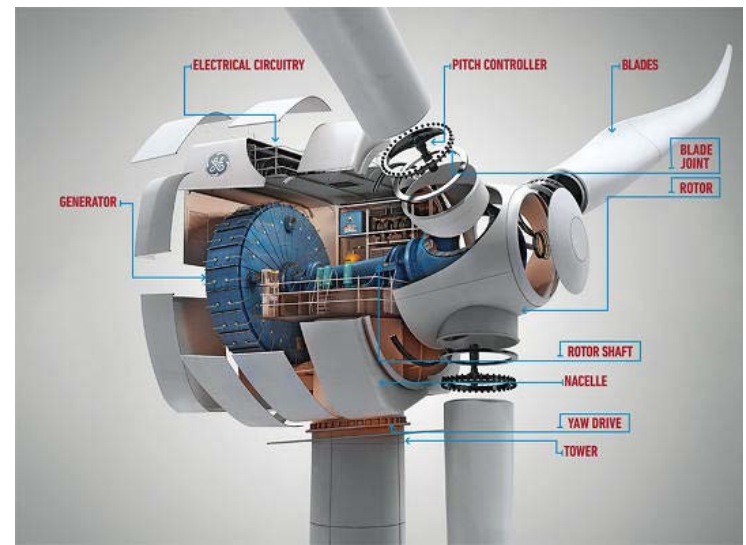

Figure 2. Schematic diagram of a wind turbine.

piece of machinery with aerodynamically designed rotor and efficient power generation, transmission and regulation components $[7,8]$. Its size ranges from a few Watts to several Million Watts. Most of today's commercial machines are horizontal axis wind turbine with three bladed rotors. The followings introduce briefly some of the main components of wind turbine.

- Rotor/Blades: The blades together with the hub are called the rotor. The rotor drives the generator by harnessing the kinetic energy in the wind. The blades are aerodynamically shaped to best capture the wind. The amount of energy wind turbine can capture is proportional to the rotor sweep area.

- Generator/Alternator: It is the part which produces electricity from the kinetic energy captured by the rotor. A generator produces DC power and an alternator produces AC power, depending on the application for the turbine.

- Nacelle: It is the housing which protects the essential motorized parts of a turbine.

- Gearbox: It is used for most turbines above $10 \mathrm{~kW}$ to match the rotor speed to the generator speed.

The power curve of a wind turbine is a graph that represents the turbine output power at different wind speed [9]. It is usually provided by the turbine's manu- facture. Figure 3 shows an example of a wind turbine power curve. It is notable that the output power is zero at speed from 0 to $2.5 \mathrm{~m} / \mathrm{s}$. This happens due to there is not sufficient kinetic energy in the wind to move the wind turbine rotor. Normally the manufactures provide technical data sheets where the start up wind speed of the turbine is given. Generally lower start up wind speeds result in higher energy coming from the turbine. Sometimes the power curve information may be shown in a table format. Some manufactures offer the exact power values at different wind speed and present this in a table. The power curve is then obtained by plotting the table values.

\subsection{Wind Speed}

No other factor is more important to the amount of wind power available to a wind turbine than wind speed. Because the power in wind is cubic function of wind speed, changes in speed produce a remarkable effect on power. Doubling the wind speed does not double the power available it increases a whopping eight times.

Wind speed varies over time. Wind speed varies by the minute, hour, day, season, and even by year. It is influenced by weather system, the local land terrain and its height above the ground surface. The average speed is composed of winds above and below the average. The cube of the average wind speed is always less than the average of the cube of wind speed. Using the average annual wind speed alone in the power equation would not give the right results. It's the wind speed above the average that contributes most of the power.

Since wind speed varies, it is necessary to capture this variation in the model used to predict the energy production. It is usually done using probability functions to describe wind speed over a period of time. The variation in wind speed is best described by a probably density function (PDF) [10], as shown in Equation (1). A PDF is used to model the wind velocity variation. It provides the

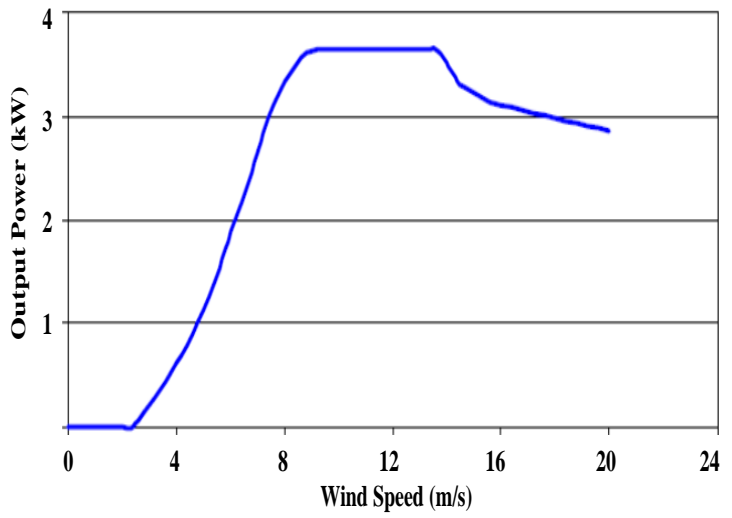

Figure 3. Schematic diagram of the power curve of a wind turbine. 
probability that an event occurs between two end points. The area under the curve between any two speeds greater than zero will equal the probability that wind will blow somewhere between those two speeds.

$$
f(v)=\frac{\alpha}{\theta}\left(\frac{v}{\theta}\right)^{\alpha-1} e^{-\left(\frac{v}{\theta}\right)^{\alpha}}
$$

where $v$ represents in this case the wind speed, $\alpha$ is the shape factor and $\theta$ is the scale factor. For a given average wind speed, a smaller shape factor indicates a relatively wide distribution of wind speeds around the average, while a larger shaper factor indicates a relatively narrow distribution of wind speeds around the average.

Wind speed calculated includes two types, i.e., the arithmetic mean wind speed and the cubic root cube wind speed [11].

The arithmetic mean wind speed is what normally known as the average wind speed. It is given by:

$$
v_{\text {ave }}=\int_{v_{\min }}^{v_{\max }} f(v) \cdot v \cdot d v
$$

where $f(v)$ is the Weibull PDF, $v$ is the data vector of measured wind speed, $v_{\min }$ is the minimum measured wind speed and $v_{\max }$ is the maximum measured wind speed.

The use of arithmetic mean wind speed tends to underestimate the electric power production. The cubic root cube wind speed produces a better estimate of actual power production. To find the cubic root cube average speed, the data vector of wind speed is elevated to the cube and multiplied by the PDF. The function is integrated between $v_{\min }$ and $v_{\max }$. Then it is elevated to cubic root. The result is the cubic root cube average speed, which is defined as:

$$
v_{c r c}=\sqrt[3]{\int_{v_{\min }}^{v_{\max }} f(v) \cdot v^{3} \cdot d v}
$$

Likewise, where $f(v)$ is the Weibull PDF, $v$ is the data vector of measured wind speed, $v_{\min }$ is the minimum measured wind speed and $v_{\max }$ is the maximum measured wind speed.

\subsection{Wind Power and Energy}

Wind power is a function of air density, the area intercepting the wind and the wind speed [12]. It is calculated as below:

$$
P=\frac{1}{2} \varepsilon \cdot S \cdot v^{3}
$$

where $P$ is the output power in watts, $\varepsilon$ is the air density in $\mathrm{kg} / \mathrm{m}^{3}, S$ is the area in $\mathrm{m}^{2}$ where wind is passing and $v$ is the wind speed in $\mathrm{m} / \mathrm{s}$.

Wind energy is power over some unit of time. The energy production can be calculated substituting the average wind speed value in power Equation (4). Then multiplying the Equation (4) by the hours of the period, the energy is obtained as shown below:

$$
E=\frac{1}{2} \varepsilon \cdot S \cdot v^{3} \cdot H \cdot D
$$

where $E$ is the total energy in Wh, $H$ is hours, $D$ is days, and the variable $v$ can be either the arithmetic mean wind speed or the cubic root cube wind speed, but using the cubic root cube wind speed is better estimation of the average wind speed than the arithmetic mean wind speed.

\section{Technical Properties of Solar Photovoltaic Power}

\subsection{Photovoltaic Cells and Modules}

Photovoltaic cells consist of semiconductor material, i.e., silicon, which is at present the most often utilized [13]. Photovoltaic cells have electric fields which can force electrons to flow in a certain direction. The flowing of electrons is a current and it can be used externally. Because of depending on the behavior of the solar resource, the electricity produced by photovoltaic cells is intermittent. The technology used is modular, since it could be connected to pre-existing installations of photovoltaic panel, as shown in Figure 4, and replaced individually.

The efficiency of photovoltaic cells decreases with increases in temperature. Photovoltaic panel reacts directly to sunlight. The chances of change in weather could block sunlight, such as clouds, rain and sandstorms.

Photovoltaic modules are made up of interconnected photovoltaic cells. The cells in the modules are connected together in a designed configuration to deliver useful current and voltage. The cells connected in parallel increase the current output, while the cells connected in series increase the voltage output. Groups of several photovoltaic modules connected together are called solar array.

\subsection{Battery}

Battery is a device which stores DC electrical energy in electrochemical form for later use [14]. Due to not all

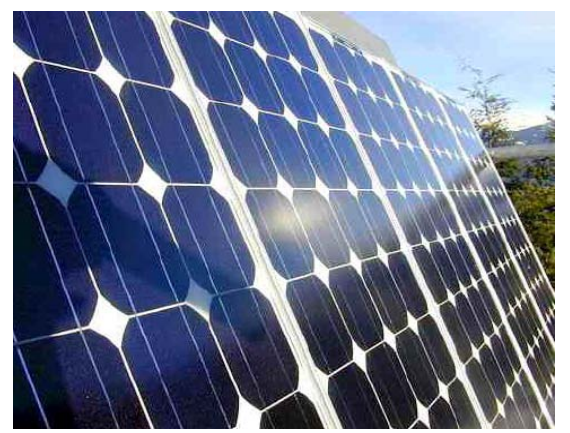

Figure 4. Schematic diagram of photovoltaic panel. 
batteries rechargeable, they are divided in two categories. The first category can't be recharged and only converts chemical energy to electrical energy. The second can be recharged. Because energy is lost in the chemical reaction during charging or recharging, the conversion efficiency of battery is not perfect. The internal components include positive and negative electrodes plates [15]. The life of battery is directly related to how deep the battery is cycled. Discharge depth refers to how much capacity could be used from the battery. Most systems are designed for regular discharges up to 40 - 80 percent.

Temperature can affect the performance of battery. The capacity of battery will increase at higher temperature and decrease at lower temperature. The life of battery will increase at lower temperature and decrease at higher temperature.

Equation (6) describes how to calculate the number of batteries connected in series to reach the voltage required by the system. Where $V_{D C}$ is the DC system voltage (Volt), $V_{B}$ is the battery voltage (Volt).

$$
N_{S}=\frac{V_{D C}}{V_{B}}
$$

Equation (7) describes how to calculate the number of batteries connected in parallel to reach the Amp hours required by the system. Where $C_{R}$ is the required battery bank capacity (Ah), $C_{S}$ is the capacity of selected battery (Ah).

$$
N_{P}=\frac{C_{R}}{C_{S}}
$$

The total number of batteries needed can be obtained by multiplying the number in series and the number in parallel as shown in equation (8).

$$
N=N_{S} \cdot N_{P}
$$

\subsection{Inverter}

The inverter converts the DC electrical energy to AC electrical energy, which can then be used to operate AC devices like the ones plugged in to most household electrical outlets [16]. The normal output AC waveform of inverter is sine wave with frequency of $50 / 60 \mathrm{~Hz}$.

Inverters are available including three different categories, i.e., grid tied battery less, grid tied with battery back-up and stand alone. The most popular inverters are grid tied battery less. These inverters directly connect to the public utility, using the utility power as storage battery. When the sun shines, the electricity comes from the photovoltaic via the inverter. If the photovoltaic array produces more power than used, the excess is sold to utility power company through the electric meter.
Inverter sizing contains calculating the number of inverters needed for the photovoltaic system. When selecting an inverter must have a DC voltage equal to inverter DC voltage and have an AC voltage and frequency equal to home and utility values.

$$
N_{I}=\frac{P_{L}}{P_{I}}
$$

Equation (9) describes how to calculate the number of inverters needed. Where $P_{L}$ represents the maximum continuous power loading home consumes, $P_{I}$ is the maximum power supplied by the inverter.

\subsection{Photovoltaic Controller}

The photovoltaic controller operates as a voltage regulator. Its primary function is to prevent the battery from overcharged. When the batteries are fully charged, the controller will stop or decrease the amount of current flowing into the battery. The average efficiency of the controller ranges from $95 \%$ to $98 \%$.

If high current is required, two or more controllers can be used. When more than one controller used, it is necessary to divide the array into sub-arrays. Each subarray is wired into the same battery bank. The photovoltaic controller contains the five different types, i.e., shunt controller, single stage series controller, diversion controller, pulse width modulation controller and maximum power point tracking controller. The maximum power point tracking controller is the best for photovoltaic system at present. It allows the controller to track the maximum power point of the array throughout the day to delivery the maximum available solar energy to system. Before maximum power point tracking controller was available, the array voltage would be pulled down slightly above the battery voltage while charging.

When selecting a controller must be sure $\rightarrow$ ensured it has an output voltage rating equal to the nominal battery voltage, also the maximum photovoltaic voltage should be less than the maximum controller voltage rating.

\subsection{Photovoltaic Energy}

Hourly average solar radiation values are usually used to calculate the photovoltaic energy (kWh) generated for one year at a specific site, as shown in Equation (10).

$$
E_{Y}=P_{P M}\left(R_{A V E}\right) \cdot T_{P M}\left(R_{A V E}\right) \cdot 365
$$

where $E_{Y}$ is the yearly expected photovoltaic energy production at a given site $(\mathrm{kWh}), P_{P M}\left(R_{A V E}\right)$ is the photovoltaic module output power at an average hourly solar irradiation $\left(R_{A V E}\right), T_{P M}\left(R_{A V E}\right)$ is the time of the sun hit the photovoltaic module at $R_{A V E}$, the product of 365 is to change daily to yearly quantities. 


\subsection{Environmental Impacts of Wind and Solar Photovoltaic Power}

The impacts of wind power on environment are relatively small. The impacts on wildlife in operation stage are related to the noise of wind turbines. Due to the power lines associated with wind farms, it may cause electromagnetic radiation or possible forest fire. For offshore wind farms, the impacts are those with regard to fishing, navigation and effects on marine life. The power lines buried under the seabed could have an impact on breakable ecosystems. If the offshore wind farms close to shore, they may have an impact on birds.

The first aspect of the environmental impacts of solar photovoltaic power is about aesthetics when its components installed. Photovoltaic panels may occupy some spaces, e.g., building roofs, road and railroad margins. The second aspect of the impacts is associated with the photovoltaic cells production. During the production process and the arrangement stage, it uses some poisonous materials, which are harmful to environment.

\section{Conclusions}

Wind energy transforms the kinetic energy from the wind into usable electricity by utilizing wind turbine. Wind turbine is composed basically of a tower base, three blades and a generator at the middle hub where the motion of the blades is transformed into electricity by means of inductance. The advantage of power curve is that it includes the wind turbine efficiency. Wind speed is a quite important element to wind energy. By the Weibull probably density function (PDF), the wind velocity variation can be described accurately. Combined with the Weibull PDF, the arithmetic mean wind speed and the cubic root cube wind speed can be derived and calculated. Based on the obtained wind speed, wind power and energy can be calculated.

Solar photovoltaic power generates electricity from the sunlight radiation. When sunlight strikes photovoltaic cells, the direct current is generated. Photovoltaic modules consist of interconnected photovoltaic cells. To increase the voltage and current output, photovoltaic cells are connected in series and parallel respectively. For storing DC electrical energy for later use, battery is necessary. The features of battery could be influenced by temperature. The life of battery is directly relevant to how deep it is cycled. To convert DC electrical energy to $\mathrm{AC}$ electrical energy for AC devices running, the inverter must be provided. The type of grid tied battery is less commonly used in some inverters types. The photovoltaic controller serves as a role of voltage regulator to prevent battery from overcharged. To calculate the photovoltaic energy at a given site, hourly average solar radiation values are used.
From these derived technical properties, the analysis basis and reference can be provided for further study on the power system including wind and solar photovoltaic power.

\section{Acknowledgements}

This work was financially supported by the 52nd General Program of China Postdoctoral Science Foundation (2012M521837)

\section{REFERENCES}

[1] G. Jose, “The Case for Renewable Energies," Thematic Background Paper at the International Conference for Renewable Energies, Bonn, Germany, 2004.

http://www.renewables2004.de

[2] J. Martin, "Learning in Renewable Energy Technology Development,” Ph.D. Thesis, Utrecht University, Utrecht, 2005.

[3] M. Patel, "Wind and Solar Power Systems," 2nd Edition, Taylor \& Francis, 2006.

[4] M. S. Lu, C. L. Chang and W. J. Lee, "Impact of Wind Generation on a Transmission System," Proceedings of Power Symposium, NAPS, 2007.

[5] C. I. Chai, W. J. Lee, P. Fuangfoo, M. Williams and J. Liao, "System Impact Study for the Interconnection of Wind Generation and Utility System," Proceedings of IEEE I\&CPS Conference, Clearwater Beach, Florida, 2005.

[6] J. F. Manwell, J. G. Mcgowan and A. L. Rogers, "Wind Energy Explained,” Wiley Press, New York, 2002. http://dx.doi.org/10.1002/0470846127

[7] F. Bianchi, H. D. Battista and R. Mantz, "Wind Turbine Control Systems,” Springer-Verlag Press, London, UK, 2007.

[8] K. Tan and S. Islam, "Optimum Control Strategies in Energy Conversion of pmsg Wind Turbine System without Mechanical Sensors," IEEE Transactions on Energy Conversion, Vol. 19, No. 2, 2004, pp. 392-399. http://dx.doi.org/10.1109/TEC.2004.827038

[9] G. Ramtharan, N. Jenkins and L. Anaya, "Modelling and Control of Synchronous Generators for Wide Range Variable Speed Wind Turbines,” Wind Energy, Vol. 10, No. 3, 2007, pp. 231-246. http://dx.doi.org/10.1002/we.219

[10] E. G. Pavia and J. J. Brien, "Weibull Statistics of Wind Speed over the Ocean," Journal of Climate and Applied Meteorology, Vol. 25, No. 10, 1986, pp. 1324-1332. http://dx.doi.org/10.1175/1520-0450(1986)025<1324:WS OWSO $>2.0 . \mathrm{CO} ; 2$

[11] G. J. Herbert, S. Iniyan, E. Sreevalsan and S. Rajapandian, "A Review of Wind Energy Technologies," Renewable and Sustainable Energy Reviews, Vol. 11, No. 6, 2007, pp. 1117-1145. http://dx.doi.org/10.1016/j.rser.2005.08.004

[12] The Wind Indicator, "Wind Energy Facts and Figures from Wind Power Monthly,” Windpower Monthly News Magazine, Denmark, USA, 2005.

[13] B. S. Borowy and Z. M. Salameh, “Optimum Photovol- 
taic Array Size for a Hybrid Wind/PV System," IEEE Transactions on Energy Conversion, Vol. 9, No. 3, 2004, pp. 482-488. http://dx.doi.org/10.1109/60.326466

[14] B. S. Borowy and Z. M. Salameh, "Methodology for Optimally Sizing the Combination of a Battery Bank and PV array in a Wind/PV Hybrid System," IEEE Transactions on Energy Conversion, Vol. 11, No. 2, 2006, pp. 367-375. http://dx.doi.org/10.1109/60.507648
[15] A. Smeets, "Investigation of the Solar Production of Silicon Nitride by Carbothermic Reduction of Silicon Dioxide,” Diplomarbeit ETH-Swiss Federal Institute of Technology, Swiss, 2003.

[16] PVDI, "Solar Energy International (Photovoltaic Design and Installation Manual),” New Society Press, New York, 2007. 